\title{
ROTAÇÃO DE CULTURAS PARA TRIGO, APÓS QUATRO ANOS: EFEITOS NA FERTILIDADE DO SOLO EM PLANTIO DIRETO
}

\author{
CROP ROTATION SYSTEMS FOR WHEAT, AFTER FOUR YEARS: \\ EFFECTS ON SOIL FERTILITY UNDER NO-TILLAGE
}

\author{
Henrique Pereira dos Santos ${ }^{1}$ Gilberto Omar Tomm ${ }^{2}$
}

RESUMO

A fertilidade do solo foi avaliada, após quatro anos (1990 a 1994), num latossolo bruno álico, em Guarapuava, PR, Brasil, em quatro sistemas de rotação de culturas para trigo: sistema I (trigo/soja); sistema II (trigo/soja e aveia branca/soja); sistema III (trigo/soja, ervilhacal milho e aveia branca/soja); $e$ sistema IV (trigo/soja, aveia branca/soja, cevada/soja e ervilhaca/milho). As culturas, tanto de inverno como de verão, foram estabelecidas sob plantio direto. $O$ delineamento experimental foi de blocos ao acaso com quatro repetições. Através de contrastes, foram comparados os sistemas e as profundidades de amostragem de solo. Em todos os sistemas de rotação de culturas, na camada de solo 0 a $5 \mathrm{~cm}$, observaram-se valores maiores de $\mathrm{pH}$ e de Ca+Mg e menores de Al (com exceção do sistema III), em relação à camada 15 a $20 \mathrm{~cm}$. Houve elevação dos teores de $\mathrm{Ca}+\mathrm{Mg}$, de K e de P na camada de solo com a maior concentração de raízes $(0$ a $10 \mathrm{~cm})$. Os valores de matéria orgânica do solo decresceram progressivamente da camada 0 a $5 \mathrm{~cm}$ para a camada 15 a $20 \mathrm{~cm}$.

Palavras-chave: rotação de culturas, sucessão de culturas, fertilidade do solo, calagem.

\section{SUMMARY}

Soil fertility parameters were evaluated after four years (1990 to 1994) on a alic dusky latosol located in Guarapuava, Paraná, Brazil, under four wheat crop rotation systems as follows: system I (wheat/soybean); system II (wheat/soybean and white oats/soybean); system III (wheat/soybean, common vetch/corn, and white oats/soybean); and system IV (wheat/soybean, white oats/soybean, barley/soybean and common vetch/cor). Both winter and summer crops were seeded under no tillage. A randomized complete block design, with four replications, was used. Crop systems and soil samples at different depths were compared using the contrast procedure. All crop rotation systems, in the 0 to $5 \mathrm{~cm}$ soil layer, higher values were observed for $\mathrm{pH}$ in water and $\mathrm{Ca} \mathrm{Mg}$ and lower contents for Al (except system III), as compared to the 15 to $20 \mathrm{~cm}$ layer. Raising in $\mathrm{Ca}+\mathrm{Mg}, \mathrm{K}$, and P levels occurred in the soil layer with the greatest root concentration $(0$ to $10 \mathrm{~cm})$. The soil organic matter contents decreased with depth from $0-5 \mathrm{~cm}$ to $15-20 \mathrm{~cm}$.

Key words: crop rotation, crop succession, soil fertility, liming.

\section{INTRODUÇÃO}

As plantas são poderosas aliadas do agricultor para melhorar e conservar o solo (KOCHHANN \& SELLES, 1991). Com os nutrientes, água e luz, elas sintetizam a matéria vegetal, que, se bem manejada, protege o solo dos agentes erosivos, reduz as variações de temperatura e de umidade, recupera e mantém as características químicas, físicas e biológicas do solo. Assim, recomenda-se o uso de sistemas de manejo conservacionistas, como o sistema plantio direto (PD), o qual pode proporcionar uma cobertura adequada do solo por resíduos vegetais, reduzir as perdas de solo por erosão, manter o conteúdo de matéria orgânica e contribuir para a manutenção ou elevação do potencial de rendimento das culturas.

A rotação de culturas sob plantio direto melhora igualmente as condições biológicas, físicas e químicas do solo, gerando condições satisfatórias de desenvolvimento às culturas. Quanto mais diversificados os sistemas de rotação de culturas, maiores serão as possibilidades de se incorporarem ao solo

\footnotetext{
${ }^{1}$ Engenheiro Agrônomo, Doutor, Bolsista do CNPq, Embrapa-Centro Nacional de Pesquisa de Trigo, CP 451, 99001-970, Passo Fundo (RS). E.mail: hpsantos@ cnpt.embrapa.br. Autor para correspondência.

${ }^{2}$ Engenheiro Agrônomo, PhD., Embrapa-CNPT. Bolsista do CNPq. 
matéria orgânica, fósforo e potássio (SANTOS \& SIQUEIRA, 1992; SÁ, 1993; SANTOS \& TOMM, 1996b).

Nos trabalhos realizados por SHEAR \& MOSCHLER (1969) e por TRIPLETT Jr. \& VAN DOREN Jr. (1969), nos EUA, após seis anos, observou-se que os sistemas de rotação de culturas sob PD acumulavam mais matéria orgânica, $P$ extraível, $\mathrm{Ca}, \mathrm{Mg}$ e $\mathrm{K}$ trocáveis do solo, na camada 0 a $5 \mathrm{~cm}$, em relação à camada 0 a $20 \mathrm{~cm}$. Nesses casos, após esse período, o manejo de solo sob PD necessitou de nova calagem, em comparação ao preparo convencional, devido à acidificação do solo.

$\mathrm{O}$ acúmulo de $\mathrm{Ca}, \mathrm{Mg}$ e $\mathrm{K}$ trocáveis, bem como de $\mathrm{P}$ extraível, nas camadas superficiais do solo, foi verificado em Londrina, PR, a partir do terceiro ano de cultivo sob PD (MUZILLI, 1983; SIDIRAS \& PAVAN 1985). Nesses casos, houve aumento de $\mathrm{pH}$ e diminuição nos teores de $\mathrm{Al}$ trocável na camada 0 a $10 \mathrm{~cm}$ do solo em PD.

SANTOS \& TOMM (1996b), em Passo Fundo, RS, aplicando 2,0t/ha de calcário na superfície do solo, após seis anos de PD, observaram a diminuição no $\mathrm{pH}$, nos teores de $\mathrm{Ca}+\mathrm{Mg}$ trocáveis, na matéria orgânica, no $\mathrm{P}$ extraível e no K trocável, à medida que se aumentou a profundidade de amostragem do solo, em latossolo vermelho escuro distrófico. Os mesmos autores observaram diferenças significativas entre os teores de matéria orgânica e de $\mathrm{K}$ trocável do solo dos sistemas de rotação de culturas para triticale.

Num período de cinco anos sob PD, SANTOS \& SIQUEIRA (1996), em Guarapuava, $\mathrm{PR}$, verificaram a diminuição nos valores de $\mathrm{pH}$ e de $\mathrm{Ca}+\mathrm{Mg}$ trocáveis do solo, com o aumento da profundidade da camada 0 a $5 \mathrm{~cm}$ para 15 a $20 \mathrm{~cm}$, em latossolo bruno álico. Por outro lado, os teores de matéria orgânica, de $\mathrm{P}$ extraível, de $\mathrm{Al}$ e de $\mathrm{K}$ trocáveis tiveram tendência inversa.

Este trabalho teve como objetivo avaliar o efeito de diversos sistemas de rotação de culturas para trigo, sob PD, após quatro anos de cultivo, sobre a fertilidade do solo, em Guarapuava, PR.

\section{MATERIAL E MÉTODOS}

O experimento foi realizado na Cooperativa Agrária Mista Entre Rios Ltda., município de Guarapuava, PR, no período de 1990 a 1994, em latossolo bruno álico, de textura franco argilosa (EMBRAPA, 1984). Nesse mesmo local, vinha sendo conduzido experimento desde 1984 (SANTOS \& TOMM, 1996a).

Os tratamentos consistiram de quatro sistemas de rotação de culturas de inverno e de verão, tendo o trigo como cultura base do sistema, a saber: I (trigo/soja); sistema II (trigo/soja e aveia branca/soja); sistema III (trigo/soja, ervilhaca/milho e aveia branca/soja); e sistema IV (trigo/soja, aveia branca/soja, cevada/soja e ervilhaca/milho). As culturas, tanto de inverno como de verão, foram estabelecidas em sistema plantio direto.

Em abril de 1989, antes da semeadura das culturas de inverno, foram coletadas amostras de solo em cada parcela, e os valores médios foram: $\mathrm{pH}=4,7 ; \mathrm{Al}$ trocável $=24,7 \mathrm{mmol}_{\mathrm{c}} \mathrm{dm}^{-3} ; \mathrm{Ca}+\mathrm{Mg}$ trocáveis $=74,0 \mathrm{mmol}_{\mathrm{c}} \mathrm{dm}^{-3} ;$ matéria orgânica $=75 \mathrm{~g}$ $\mathrm{kg}^{-1} ; \mathrm{P}$ extraível $=14,0 \mathrm{mg} \mathrm{kg} \mathrm{kg}^{-1}$; $\mathrm{K}$ trocável = $163 \mathrm{mg} \mathrm{kg}^{-1}$. O solo da área experimental foi corrigido com 11,7t ha ${ }^{-1}$ de calcário, com PRNT 75\%, aplicadas em duas vezes: metade antes da aração (arado de discos) e metade antecedendo a gradagem da área (grade pesada ou grade niveladora). A aplicação de calcário correspondeu à metade da dose necessária para elevar o pH em água para 6,0. As amostragens de solo para a determinação de níveis de nutrientes e do teor de matéria orgânica foram realizadas anualmente, sempre após a colheita das culturas de inverno e de verão. A adubação de manutenção e a correção da acidez de solo foram baseadas na média dos valores observados nas análises de solo da área experimental.

Em maio de 1994, após as culturas de verão, foram coletadas amostras de solo compostas (seis subamostras por parcela), nas profundidades 0 $5 \mathrm{~cm}, 5-10 \mathrm{~cm}, 10-15 \mathrm{~cm}$ e $15-20 \mathrm{~cm}$. As análises $(\mathrm{pH}$ em água, $\mathrm{P}$ extraível, $\mathrm{K}$ trocável, matéria orgânica, Al trocável e $\mathrm{Ca}+\mathrm{Mg}$ trocáveis) seguiram a metodologia descrita por TEDESCO et al. (1985). O delineamento experimental foi de blocos ao acaso, com quatro repetições. A área útil da parcela foi de $60 \mathrm{~m}^{2}$ (10m de comprimento por $6 \mathrm{~m}$ de largura). Os quatro sistemas de rotação de culturas para trigo foram comparados para cada parâmetro de fertilidade de solo numa determinada profundidade de amostragem. As quatro profundidades de amostragem de solo foram comparadas dentro de um mesmo sistema de rotação.Todas as comparações foram realizadas através de contrastes com um grau de liberdade (STEEL \& TORRIE, 1980). A significância dos contrastes foi dada pelo teste F, levando-se em conta o desdobramento dos graus de liberdade do erro.

\section{RESULTADOS E DISCUSSÃO}

Não foram observadas diferenças significativas entre os valores de $\mathrm{pH}$ do solo, nos quatro sistemas de rotação de culturas avaliados (tabela 1). Resultados similares foram observados por 
Tabela 1 - Valores médios de pH em água, de alumínio trocável e de cálcio + magnésio trocáveis avaliados após as culturas de verão de 1994, em quatro camadas de solo e para diferentes sistemas de rotação de culturas.

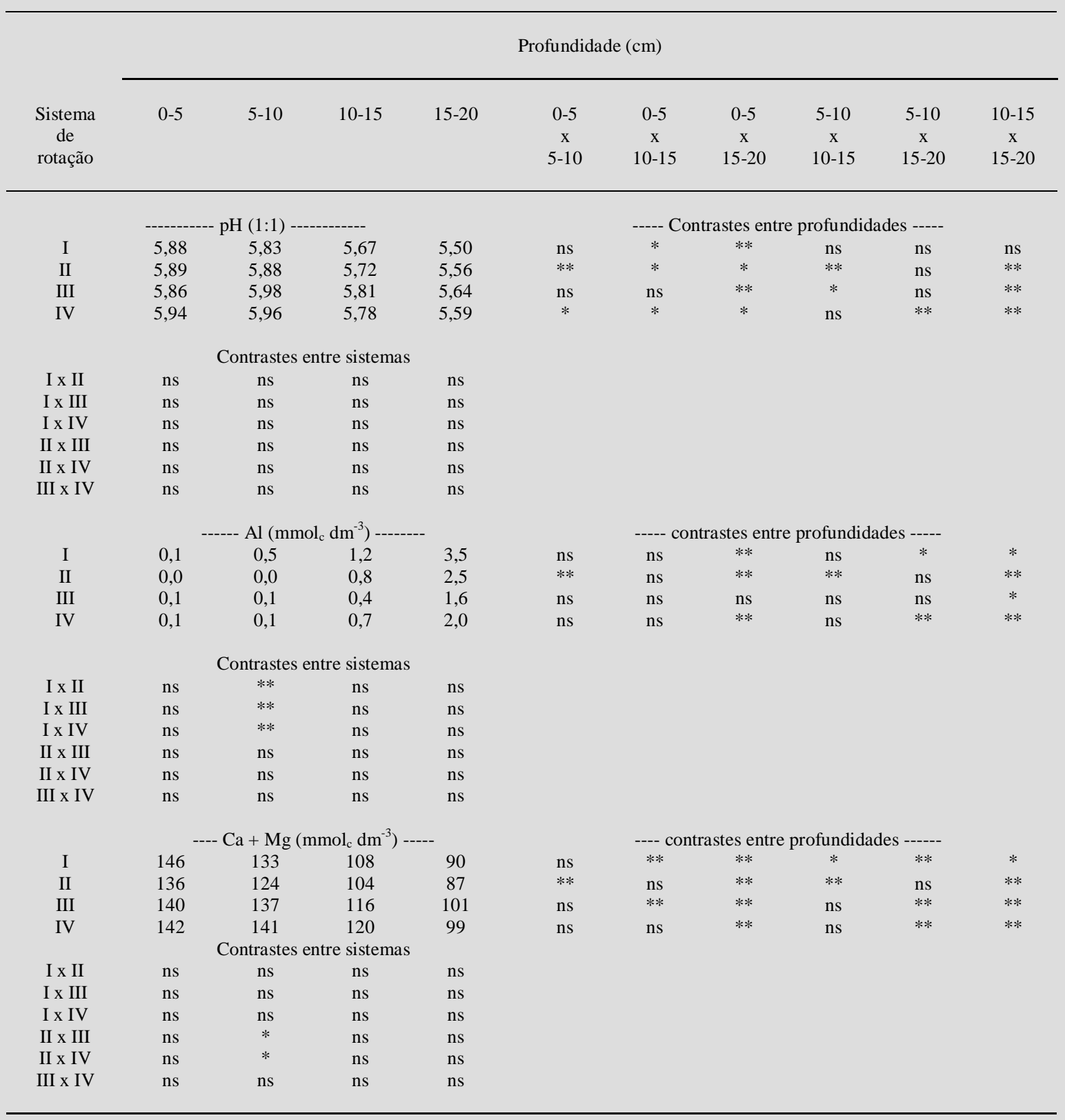

ns = não significativo; * = nível de significância de $5 \%$; ** = nível de significância de $1 \%$.

Sistema I: trigo/soja; sistema II: trigo/soja e aveia branca/soja; sistema III: trigo/soja, ervilhaca/milho e aveia branca/soja; e sistema IV: trigo/soja, aveia branca/soja, cevada/soja e ervilhaca/milho.

SANTOS \& TOMM (1996b), trabalhando com sistemas de rotação de culturas para triticale, durante seis anos, sob PD, em latossolo vermelho escuro distrófico, no estado do Rio Grande do Sul.

Os maiores valores de $\mathrm{pH}$ observados, após quatro anos de cultivo, estão relacionadas com a aplicação de 11,7t ha ${ }^{-1}$ de calcário (PRNT 75\%), em abril de 1989. Por essa razão, esses resultados foram diferentes daqueles verificados por SHEAR \& MOSCHLER (1969), no estado da Virginia, EUA, onde o valor de $\mathrm{pH}$ na camada 0 a $5 \mathrm{~cm}(5,4)$ foi menor, em comparação ao valor de $\mathrm{pH}$ na camada 0 a $20 \mathrm{~cm}(6,0)$, antes do estabelecimento do experimento. No trabalho conduzido nos EUA, foi aplica- 
do $1,1 \mathrm{t} \mathrm{ha}{ }^{-1}$ de calcário, três anos antes da primeira avaliação. SIDIRAS \& PAVAN (1985), no estado do Paraná, após quatro anos sob PD, também observaram valores menores de $\mathrm{pH}$ em solo latossolo roxo distrófico, na camada 0 a $10 \mathrm{~cm}(5,4)$, do que aqueles registrados antes da instalação do experimento $(5,6)$.

SANTOS \& SIQUEIRA (1992), no estado do Paraná, trabalhando com sistemas de rotação de culturas para cevada, sob PD, observaram que, após 4,5 anos de aplicação de calcário $\left(3,7 \mathrm{t} \mathrm{ha}^{-1}\right)$, não foi suficiente para manter o $\mathrm{pH}$ em nível desejado $(5,0$ a 6,0), aproximadamente, com dois anos e meio.

Entretanto, em alguns sistemas de rotação, foram verificadas diferenças significativas de $\mathrm{pH}$ do solo entre determinadas profundidade de amostragem. Observou-se, de modo geral, a diminuição gradativa do $\mathrm{pH}$ do solo com o aumento na profundidade de amostragem de solo (de 5,86 a 5,94, na camada de 0 a $5 \mathrm{~cm}$, para 5,50-5,64, na camada de 15 a 20cm) (tabela 1). Tendência inversa foi observada por SANTOS \& SIQUEIRA (1992) (4,90 para 5,20), em 1988, após cinco anos.

Com exceção da camada de 5 a $10 \mathrm{~cm}$ de profundidade, nas demais camadas não foram observadas diferenças significativas nos teores de $\mathrm{Al}$ trocável entre os sistemas de rotação (tabela 1). A diminuição dos teores de $\mathrm{Al}$ trocável deve-se à quantidade de calcário aplicada em abril de 1989. Na profundidade 5 a $10 \mathrm{~cm}$, o sistema $\mathrm{I}\left(0,5 \mathrm{mmol}_{\mathrm{c}} \mathrm{dm}^{3}\right)$ apresentou valor de $\mathrm{Al}$ trocável do solo maior do que os dos sistemas II $\left(0,0 \mathrm{mmol}_{\mathrm{c}} \mathrm{dm}^{3}\right)$, III $\left(0,1 \mathrm{mmol}_{\mathrm{c}}\right.$ $\left.\mathrm{dm}^{3}\right)$ e IV $\left(0,1 \mathrm{mmol}_{\mathrm{c}} \mathrm{dm}^{3}\right)$. Contudo, essas diferenças não são agronomicamente relevantes. Dados semelhantes foram encontrados por SANTOS \& TOMM (1996b), trabalhando com cinco sistemas de rotação de culturas para triticale, após seis anos de cultivo, sob PD, em latossolo vermelho escuro distrófico, no Rio Grande do Sul.

Comparando-se os níveis de Al trocável entre as profundidades de amostragem de um mesmo sistema de rotação, foram registradas diferenças significativas em todos os sistemas (tabela 1). Os valores de $\mathrm{Al}$ trocável do solo aumentaram da camada 0 a $5 \mathrm{~cm}$ para a camada 15 a $20 \mathrm{~cm}$ (de $0,0-0,1$ para 1,6-3,5 $\mathrm{mmol}_{\mathrm{c}} \mathrm{dm}^{-3}$ ). Valores contrários (de 9,3 para $5,7 \mathrm{mmol}_{\mathrm{c}} \mathrm{dm}^{-3}$ ), na mesma localidade, foram observados por SANTOS \& SIQUEIRA (1992), avaliando sistemas de rotação de culturas para cevada, sob PD. Os menores teores de Al trocável verificados com o aumento da profundidade de amostragem, encontrados no presente experimento, quatro anos após o uso do PD, sugerem que, na incorporação de calcário, uma maior proporção do corretivo aplicado ficou distribuída nas camadas próximas à superfície, em relação às camadas mais profundas.

$\mathrm{O}$ valor médio de $\mathrm{Ca}+\mathrm{Mg}$ trocáveis do solo $\left(87\right.$ a $146 \mathrm{mmol}_{\mathrm{c}} \mathrm{dm}^{-3}$ ) (tabela 1$)$, em todas as camadas, é considerado alto para o crescimento e desenvolvimento das culturas da região (REUNIÃO, 1995). Isso foi decorrente da aplicação de $11,7 \mathrm{t} \mathrm{ha}^{-1}$ (PRNT $75 \%$ ) de calcário, após cinco anos de condução do experimento. A aplicação de calcário do tipo dolomítico, onde tanto o cálcio como o magnésio foram fornecidos em grandes quantidades, fez com que os teores críticos exigidos ultrapassassem os níveis críticos pelas espécies que compuseram os sistemas de rotação (SOCIEDADE..., 1995). Dados similares (de 64 a $71 \mathrm{mmol}_{\mathrm{c}} \mathrm{dm}^{-3}$ ) foram observados por SANTOS \& SIQUEIRA (1992), em 1988, na mesma localidade, 4,5 anos após a aplicação de 3,7t ha ${ }^{1}$ de calcário dolomítico.

Os sistemas de rotação não diferiram entre si quanto aos teores de $\mathrm{Ca}+\mathrm{Mg}$ trocáveis, dentro da mesma profundidade de amostragem, com exceção do sistema II, o qual apresentou teor de $\mathrm{Ca}+\mathrm{Mg}$ trocáveis $\left(124 \mathrm{mmol}_{\mathrm{c}} \mathrm{dm}^{-3}\right)$ menor do que os sistemas III $\left(137 \mathrm{mmol}_{\mathrm{c}} \mathrm{dm}^{-3}\right)$ e IV $\left(141 \mathrm{mmol}_{\mathrm{c}} \mathrm{dm}^{3}\right)$, na camada 5 a $10 \mathrm{~cm}$. Tendência similar foi descrita por SANTOS \& TOMM (1996b), que não verificaram diferenças significativas para os teores de $\mathrm{Ca}+\mathrm{Mg}$ trocáveis entre os cinco sistemas de rotação de culturas para triticale, após seis anos, sob PD, em latossolo vermelho escuro distrófico, no Rio Grande do Sul.

Nas comparações dentro de um mesmo sistema de rotação, foram observadas diferenças significativas de $\mathrm{Ca}+\mathrm{Mg}$ trocáveis do solo entre determinadas profundidades de amostragem, em alguns sistemas de rotação. Em todos os sistemas de rotação, os teores de $\mathrm{Ca}+\mathrm{Mg}$ trocáveis diminuíram da camada 0 a $5 \mathrm{~cm}\left(136-146 \mathrm{mmol}_{\mathrm{c}} \mathrm{dm}^{-3}\right)$ para a camada 15 a $20 \mathrm{~cm}\left(87-101 \mathrm{mmol}_{\mathrm{c}} \mathrm{dm}^{-3}\right)$. Dados semelhantes foram obtidos por SIDIRAS \& PAVAN (1985), trabalhando com manejo de solo e com sistemas de rotação de culturas para trigo (74 para 62 $\mathrm{mmol}_{\mathrm{c}} \mathrm{dm}^{-3}$ ), e por SANTOS \& TOMM (1996b), com sistemas de rotação de culturas para triticale. Resultados contrários foram obtidos por SANTOS \& SIQUEIRA (1992) (64 para $71 \mathrm{mmol}_{\mathrm{c}} \mathrm{dm}^{-3}$ ). Isso pode estar relacionado com a quantidade de calcário aplicada para corrigir a área experimental ou com uma distribuição desuniforme de calcário na segunda aplicação. Essa explicação também é respaldada pelos resultados de $\mathrm{pH}$ e de $\mathrm{Al}$ trocável.

Nessa avaliação, em maio de 1994, não houve diferenças significativas entre os valores de matéria orgânica dos diferentes sistemas de rotação, na mesma profundidade de amostragem (tabela 2). 
Tabela 2 - Valores médios de matéria orgânica, de fósforo extraível e de potássio trocável avaliados após as culturas de verão de 1994, em quatro camadas de solo e para diferentes sistemas de rotação de culturas.

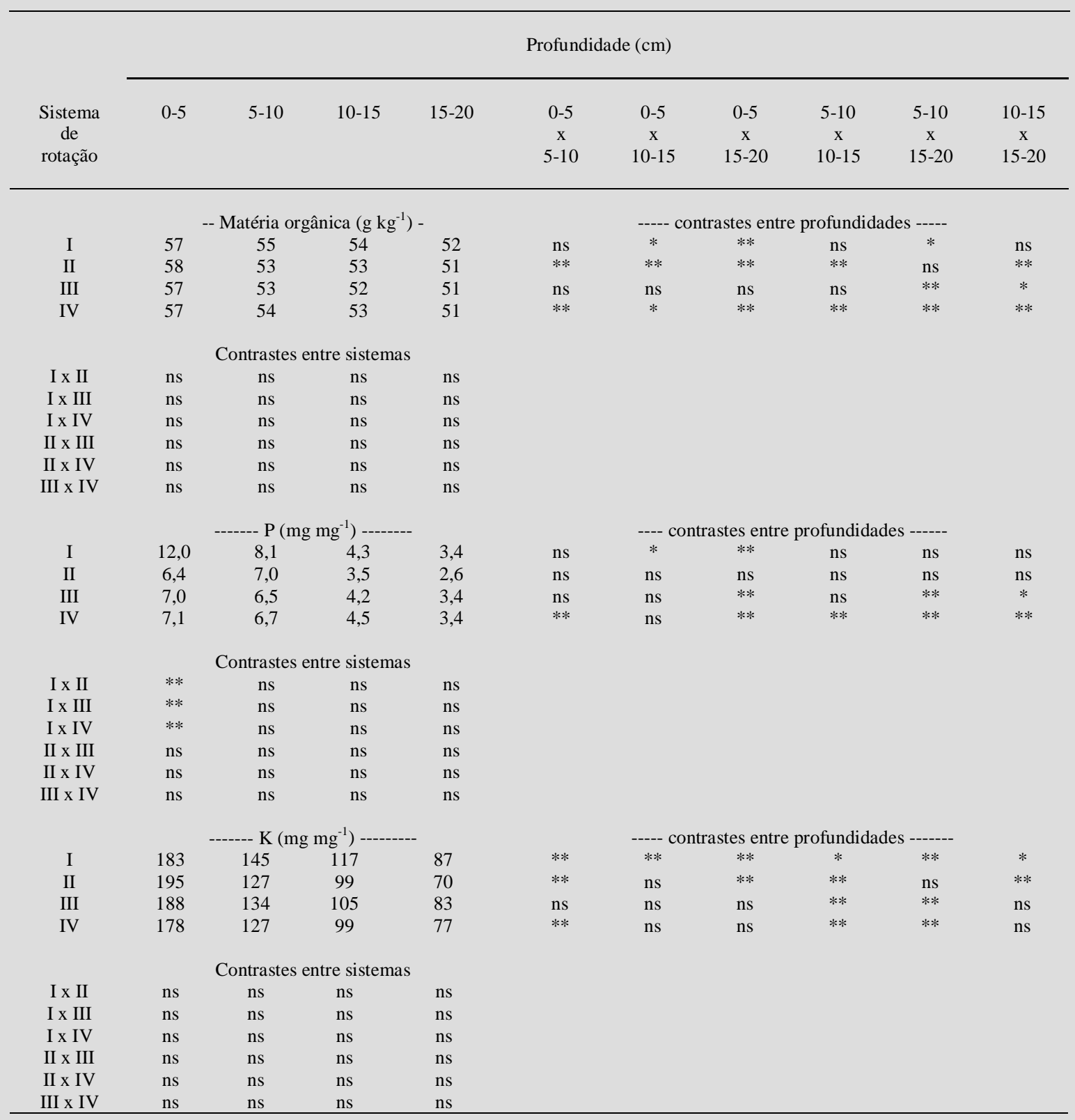

ns = não significativo; * = nível de significância de $5 \%$; ** = nível de significância de $1 \%$.

Sistema I: trigo/soja; sistema II: trigo/soja e aveia branca/soja; sistema III: trigo/soja, ervilhaca/milho e aveia branca/soja; e sistema IV: trigo/soja, aveia branca/soja, cevada/soja e ervilhaca/milho.

Entretanto, SANTOS \& TOMM (1996b), trabalhando com sistemas de rotação de culturas para triticale, durante seis anos, sob PD, em latossolo vermelho escuro distrófico, no Rio Grande do Sul, observaram teores de matéria orgânica do solo $\left(23 \mathrm{~g} \mathrm{~kg}^{-1}\right)$ menores na monocultura desse cereal (sistema I) do que em todos os demais sistemas de rotação de culturas de inverno $\left(24 \mathrm{~g} \mathrm{~kg}^{1}\right)$, na profundidade 10 a $15 \mathrm{~cm}$. $\mathrm{Na}$ profundidade de amostragem de solo 5 a $10 \mathrm{~cm}$, no sistema com triticale a cada três anos (triticale/soja, triticale/soja, aveia branca/soja e ervilhaca/milho), verificaram-se teores de matéria orgânica mais elevados $\left(26 \mathrm{~g} \mathrm{~kg}^{-1}\right)$ do que na monocultura triticale/soja $\left(24 \mathrm{~g} \mathrm{~kg}^{-1}\right)$.

Ciência Rural, v. 29, n. 2, 1999. 
Foram verificadas diferenças significativas nos teores de matéria orgânica entre determinadas profundidades de amostragem do solo, em todos os sistemas de rotação. Os valores de matéria orgânica do solo decresceram progres-

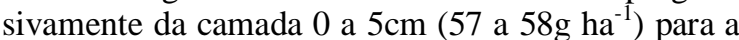
camada 15 a $20 \mathrm{~cm}$ (51 a $\left.52 \mathrm{~g} \mathrm{ha}^{-1}\right)$. Tendência semelhante nas variações entre teor de matéria orgânica na camada 0 a $5 \mathrm{~cm}$ e na camada 15 a $20 \mathrm{~cm}$ foi verificada por SANTOS \& SIQUEIRA (1992) (de 75 para $69 \mathrm{~g} \mathrm{~kg}^{-1}$ ), por SÁ (1993) (de 53 para 35g $\mathrm{kg}^{-1}$ ) e por SANTOS \& TOMM (1996b) (de 30 para $\left.22 \mathrm{~g} \mathrm{~kg}^{-1}\right)$, em sistemas de rotação de culturas para trigo e para triticale, sob PD. A manutenção do teor de matéria orgânica em valores mais elevados, apenas na camada superficial do solo, decorre do acúmulo de resíduos vegetais sobre a superfície do solo sob PD, pela ausência de incorporação física destes através do revolvimento do solo, praticada no PC, a qual diminui a taxa de mineralização. Resultados semelhantes foram obtidos por MUZILLI (1983). De acordo com SALET (1994), o sistema plantio direto apresenta um teor maior de matéria orgânica superficial e, conseqüentemente, uma concentração maior de substâncias húmicas solúveis.

Os teores de P extraível do solo (2,6 a 7,1 $\mathrm{mg} \mathrm{kg}^{-1}$ ), observados após quatro anos sob PD em três sistemas (II, III e IV) e em todas as camadas (tabela 2), foram inferiores ao valor considerado crítico, nesse tipo de solo $\left(9,0 \mathrm{mg} \mathrm{kg}^{-1}\right)$, para o crescimento e desenvolvimento das culturas (REUNIÃO, 1995). Na camada 0 a $5 \mathrm{~cm}$ de profundidade da monocultura de trigo/soja, sistema I $\left(12,0 \mathrm{mg} \mathrm{kg}^{-1}\right)$, esse valor situou-se acima desse teor crítico.

O sistema I apresentou valor maior de $\mathrm{P}$ extraível na camada 0 a $5 \mathrm{~cm}\left(12,0 \mathrm{mg} \mathrm{kg}^{-1}\right)$ do que os sistemas II $\left(6,4 \mathrm{mg} \mathrm{kg}^{-1}\right)$, III $(7,0 \mathrm{mg} \mathrm{kg})$ e IV $\left(7,1 \mathrm{mg} \mathrm{kg}^{-1}\right)$. Nas demais camadas avaliadas, não houve diferenças significativas entre os sistemas estudados.

Todos os sistemas avaliados diferiram significativamente quanto aos valores de $\mathrm{P}$ extraível, entre determinadas profundidades de amostragem. Em todos os sistemas, os valores absolutos de $\mathrm{P}$ extraível na camada 0 a $5 \mathrm{~cm}\left(6,4-12,0 \mathrm{mg} \mathrm{kg}^{-1}\right)$ foram superiores ao dobro dos teores verificados na camada 15 a $20 \mathrm{~cm}\left(2,6-3,4 \mathrm{mg} \mathrm{kg}^{-1}\right)$. Dados semelhantes foram observados em outros estudos sob PD por SHEAR \& MOSCHLER (1969) (de 59,0 para $11,0 \mathrm{mg} \mathrm{kg}^{-1}$ ), por TRIPLETT Jr. \& VAN DOREN Jr. (1969) (de 117,0 para $37,0 \mathrm{mg} \mathrm{kg}^{-1}$ ), por SANTOS \& SIQUEIRA (1992) (de 8,9 para 4,3mg $\mathrm{kg}^{-1}$ ) e por SÁ (1993) (de 35,2 para $12,5 \mathrm{mg} \mathrm{kg}^{-1}$ ). Segundo SIDIRAS \& PAVAN (1985), o acúmulo de
P extraível próximo à superfície do solo decorre das aplicações anuais de fertilizantes fosfatados, da liberação de $\mathrm{P}$ durante a decomposição dos resíduos vegetais e da menor fixação de $\mathrm{P}$, devida ao menor contato desse elemento com os constituintes inorgânicos do solo, uma vez que não há revolvimento de solo no PD.

Após quatro anos de PD, todos os teores de $\mathrm{K}$ trocável, nas camadas até $15 \mathrm{~cm}$ (tabela 2), foram superiores ao valor considerado crítico para o crescimento e desenvolvimento das culturas $(80 \mathrm{mg}$ $\mathrm{kg}^{-1}$ ) (REUNIÃO, 1995).

Os valores de $\mathrm{K}$ trocável do solo não diferiram significativamente entre os sistemas estudados. Entretanto, SANTOS \& TOMM (1996b), trabalhando com sistemas de rotação de culturas para triticale, encontraram diferenças significativas entre os sistemas avaliados. Esses autores observaram que os valores de $\mathrm{K}$ trocável foram mais elevados no sistema I (monocultura triticale/soja $=71 \mathrm{mg} \mathrm{kg}^{-1}$ ) do que nos sistemas II (triticale/soja e aveia bran$\mathrm{ca} /$ soja $=54 \mathrm{mg} \mathrm{kg}^{-1}$ ), IV (triticale/soja aveia bran$\mathrm{ca} /$ soja e ervilhaca/milho $=53 \mathrm{mg} \mathrm{kg}^{-1}$ ) e V (triticale/soja, triticale/soja, aveia branca/soja e ervilha$\mathrm{ca} / \mathrm{milho}=48 \mathrm{mg} \mathrm{kg}^{-1}$ ), na camada $15 \mathrm{a} 20 \mathrm{~cm}$.

Entre algumas profundidades de amostragem de solo, nos sistemas de rotação avaliados, foram verificadas diferenças significativas de $K$ trocável, com uma tendência a decréscimo dos teores com o aumento da profundidade. Nessas observações, os sistemas I e II apresentaram teores de $\mathrm{K}$ trocável mais elevados na camada 0 a $5 \mathrm{~cm}$, em relação à camada 15 a $20 \mathrm{~cm}$. A exemplo do verificado com $\mathrm{P}$ extraível, também houve acúmulo de $\mathrm{K}$ trocável nas camadas próximas à superfície nos diferentes sistemas de rotação. Os teores de K trocável, na camada 0 a $5 \mathrm{~cm}$ (de 183 a $195 \mathrm{mg} \mathrm{kg}^{-1}$ ), foram, em valores absolutos, 2,2 a 2,7 vezes maiores que a concentração observada na camada 15 a $20 \mathrm{~cm}$ (de 70 a $87 \mathrm{mg} \mathrm{kg}^{-1}$ ). Acúmulos similares de $\mathrm{K}$ trocável, na camada 0 a $5 \mathrm{~cm}$, em relação à camada 15 a $20 \mathrm{~cm}$, foram relatados por SHEAR \& MOSCHLER (1969) (de 159 a $98 \mathrm{mg} \mathrm{kg}^{-1}$ ), por TRIPLETT Jr. \& VAN DOREN Jr. (1969) (de 278 a $121 \mathrm{mg} \mathrm{kg}^{-1}$ ), por SANTOS \& SIQUEIRA (1992) (de 157 a 55mg $\mathrm{kg}^{-1}$ ) e por SANTOS \& TOMM (1996b) (de $200 \mathrm{a}$ $\left.71 \mathrm{mg} \mathrm{kg}^{-1}\right)$.

\section{CONCLUSÕES}

Em todos os sistemas de rotação para trigo, após quatro anos sob plantio direto na camada de solo 0 a $5 \mathrm{~cm}$, são verificados valores maiores de $\mathrm{pH}$ e de $\mathrm{Ca}+\mathrm{Mg}$ trocáveis, em relação às camadas mais profundas, e, conseqüentemente, os teores de $\mathrm{Al}$ tro- 
cável são menores na camada $0-5 \mathrm{~cm}$ do que naquelas mais profundas.

Os teores de matéria orgânica, de $\mathrm{P}$ extraível e de $\mathrm{K}$ trocável, na maioria dos sistemas, declinaram gradadivamente com o aumenta da profundidade de amostragem, da camada superficial $(0-5 \mathrm{~cm})$ para a camada mais profunda $(15-20 \mathrm{~cm})$.

\section{REFERÊNCIAS BIBLIOGRÁFICAS}

EMBRAPA. Serviço Nacional de Levantamento e Conservação do Solo (Rio de Janeiro, RJ). Levantamento de reconhecimento dos solos do Estado do Paraná. Curitiba: EMBRAPA-SNLCS/SUDESUL/IAPAR, 1984. v. 1, 412 p. Embrapa-SNLCS. Boletim de Pesquisa, 27, IAPAR. Boletim Técnico, 16.

KOCHHANN, R.A., SELLES, F. O solo e o sistema de manejo conservacionista. In: FERNADES, J.M., FERNANDEZ, M.R., KOCHHANN, R.A., et al., ed. Manual de manejo conservacionista do solo para os estados do Rio Grande do Sul, Santa Catarina e Paraná. Passo Fundo: CIDA/Embrapa-CNPT, 1991. p. 9-20. Embrapa-CNPT. Documentos, 1 .

MUZILLI, O. Influência do sistema de plantio direto, comparado ao convencional, sobre a fertilidade da camada arável do solo. Revista Brasileira de Ciência do Solo, Campinas, v. 7, n. 1, p. 95-102, 1983.

REUNIÃO ANUAL DE PESQUISA DE CEVADA. Recomendações da Comissão de Pesquisa de Cevada para o cultivo de cevada cervejeira em 1995 e 1996. Passo Fundo: Embrapa-CNPT, 1995. 57 p. Embrapa-CNPT. Documentos, 21.

SÁ, J.C. de M. Manejo da fertilidade do solo no sistema plantio direto. In: EMBRAPA. Centro Nacional de Pesquisa de Trigo (Passo Fundo, RS). Plantio direto no Brasil. Passo Fundo: Embrapa-CNPT/FUNDACEP-FECOTRIGO/Fundação ABC, 1993. p. 37-60.

SALET, R.L Dinâmica de íons na solução de um solo submetido ao sistema plantio direto. Porto Alegre-RS. 111 p. Tese (Mestrado em Solos) - Curso de Pós-graduação em Agronomia, Universidade Federal do Rio Grande do Sul, 1994.

SANTOS, H.P. dos, SIQUEIRA, O.J.W. de. Plantio direto e rotação de culturas para cevada: efeitos sobre a fertilidade do solo. Revista Brasileira de Ciência do Solo, Campinas, v. 20, n. 1, p. 163-169, 1996.

SANTOS, H.P dos, TOMM, G.O. Estudos da fertilidade do solo sob quatro sistemas de rotação de culturas envolvendo trigo em plantio direto. Revista Brasileira de Ciência do Solo, Campinas, v. 20, n. 3, p. 407-414, 1996a.

SANTOS, H.P. dos, TOMM, G.O. Evolução da fertilidade do solo sob diversos sistemas de rotação de culturas com triticale. Revista Brasileira de Ciência do Solo, Campinas, v. 20, n. 3, p. 415-421, 1996b.

SHEAR, G.M., MOSCHLER, W.W. Continuous corn by the notillage and continuous tillage methods: a six-year comparison. Agronomy Journal, Madison, v. 58, n. 1, p. 524-526, 1969.

SIDIRAS, N., PAVAN, M.A. Influência do sistema de manejo do solo no seu nível de fertilidade. Revista Brasileira de Ciência do Solo, Campinas, v. 9, n. 3, p. 249-254, 1985.

SOCIEDADE BRASILEIRA DE CIÊNCIA DO SOLO. Núcleo Regional Sul. Comissão de fertilidade do solo-RS/SC. Recomendações de adubação e de calagem para os estados do Rio Grande do Sul e Santa Catarina. 3.ed., 2. reimp. Passo Fundo: NRS-SBCS, 1995. 224 p.

STEEL, G.D., TORRIE, J.H. Principles and procedures of statistics: a biometrical approach. 2.ed. New York: McGrawHill, 1980. 633 p.

TEDESCO, M.J., VOLKWEISS, S.J., BOHNEN, H. Análise de solos, plantas e outros materiais. Porto Alegre: UFRGSFaculdade de Agronomia, 1985. 32 p. UFRGS-Faculdade de Agronomia. Boletim Técnico, 5.

TRIPLETT Jr., G.B., VAN DOREN, Jr., D.M. Nitrogen, phosphorus, and potassium fertilization of non-tilled maize. Agronomy Journal, Madison, v. 61, n. 4, p. 637-639, 1969.

Ciência Rural, v. 29, n. 2, 1999. 